\title{
Guillian Barre syndrome epidemiology presentation and outcome
}

\author{
By
}

Dr.Raed jabbar Hussain ${ }^{* 1}$; Dr. Rahan Assim Mohammed Al-Qazzaz ${ }^{* 2}$; Kahtan Adnan Abdullah ${ }^{* 3}$

${ }^{* 1}$ FIBMS Pediatrics, Al-Elwiya pediatric teaching hospital, Baghdad- Alrusafa/Health Directorate, Ministry of Health and Environment, Baghdad, Iraq; ${ }^{* 2}$ CABMS pediatrics, alsheikhan general hospital; ${ }^{* 3}$ Senior pediatrician F.I.B.M.S,JAR pediatric teaching hospital Suliamania

\begin{abstract}
:
Background Guillain Barre syndrome (GBS) is most common cause of acute flaccid paralysis, affect peripheral nerves with distinctive features clinical, pathological and prognosis. Patient and methods this study is prospective of 60 patients admitted at al-kadymia teaching hospital from first January 2004 to end April 2009. Age includes 1 to $\leq 11$ years. Diagnosis was by clinical examination and confirmed by CSF tests and nerve conduction velocity study. Results It was found that 32 patients were male and 28 were female. Cranial nerves involved in $30 \%$ of patients. Sensory symptoms found in $16 \%$. CSF changes was seen in $85.5 \%$ patients. Antecedent events were found in 27 patients out of 60, 14 had history of upper respiratory tract infection $45 \%, 7$ had gastroenteritis $11 \%, 6$ patients had history of fever 3 weeks earlier $10 \%$ and 15 patients had complicated by respiratory failure managed by mechanical ventilators, During this study 4 patients had been died. Conclusions: Current study conclude about $45 \%$ of patients had history antecedent events in as upper respiratory tract infection, gastroenteritis and fever, so cerebrospinal fluid CSF cell in the majority of cases within normal range and mostly lymphocytes, Cranial nerves were affected in most patients without serious sequels so Steroid was not given to most of patients in our study without any significant effect on the course of disease, Hospitalization was range from 2 week to 4 week, Recovery was range from 4 to 12 week and Death rate was $6 \%$.
\end{abstract}

Key words: Guillian barre syndrome (GBS); polyneuropathy; cerebrospinal fluid (CSF); steroids; intensive care unit (ICU). 


\section{Introduction:}

Guillian Barre syndrome GBS is an acute idiopathic monophasic acquired inflammatory demyelinating polyradiculoneuropathy characterized by symmetrical progressive ascending weakness, areflexia, variable sensory complaints, and elevated cerebrospinal fluid CSF protein without pleocytosis. The disorder is thought to result from a Postinfectious immune mediated process that predominantly affect motor nerves ${ }^{(1)}$ guillian Barre syndrome is the most common cause of acute flaccid paralysis in healthy infants and children ${ }^{(2)}$. It has an annual incidence of 0.6 to 2.4 cases per 100.000 population and occur at all ages and in both sexes ${ }^{(3)}$.

The incidence is lower in children, 0.38 and 0.91 cases per 100.000 in two reports ${ }^{(4,5)}$. GBS occurs rarely in children younger than two years of age, but can occur in infants ${ }^{(6,7)}$. Males are affected approximately 1.5 times more often than females in all age groups ${ }^{(1)}$, the pathologic changes depend upon the form of GBS. In acute inflammatory demyelinating polyradiculoneuropathy and Miller Fisher variant, a focal inflammatory response develops against myelin producing Schwann cells or peripheral myelin. Infiltration of the epineural and endoneural small vessels (mostly veins) by lymphocytes and monocytes causes segmental myellin degeneration throughout the nerve. The inflammation is more intense at the junction of the dorsal and ventral roots ${ }^{(8)}$. The demyelination blocks electrical conduction along the nerve. Axonal degeneration occurs as a secondary response; the extent relates to the intensity of the inflammatory response all myelinated nerves (motor, sensory, cranial and sympathetic) can be affected. The breakdown of the blood-nerve barrier at the dural attachment allows transudation of plasma proteins into the $\mathrm{CSF}^{(1) \text {, }}$ 
The severity of GBS in children dose not correlate with long-term outcome. As many as 85 percent of children can be expected to have an excellent recovery. Approximately one Half of patients are ambulatory by six months, and seventy percent walk within a year after onset ${ }^{(9,10)}$. Abetter prognosis is associated with a gradual evolution of weakness ${ }^{(11)}$. Mortality is approximately 3 to $4 \%$, and usually is secondary to respiratory failure or cardiac complications ${ }^{(9)}$

Patients and Methods: Between (beginning of January 2004 to end of April 2009) sixty children with GBS were admitted to Al-kadymia teaching hospital in Baghdad or referred from other hospitals for further care or for RCU admission, the study is prospective. The variables for analysis in this study include (age, sex, duration of hospitalization, presentation, antecedent infection, motor weakness, sensory, autonomic and cranial nerves involvement, respiratory muscle involvement, admission to RCU, CSF analysis, and outcome). Investigation was done including lumber puncture (LP) in first 2 weeks, Electromyography (EMG) was done in 35 patients (58.3\%). The criteria which had been applied in this study are the same diagnostic criteria of GBS after Asbury and cornblath includes the following (52). the Features required for diagnosis: Progressive motor weakness of more than one limb, Loss of tendon jerks .so features strongly support the diagnosis: Clinical features: progressive over 4 weeks. Relative symptoms of weakness.; Mild sensory signs or symptoms. Cranial nerves involvement; Recovery usually beginning 2-4 weeks after progression are stops ; Autonomic dysfunction; Absence of fever at the onset of neurological symptoms; CSF features: CSF protein raised after the first week of symptoms and counts of 10 or fewer mononuclear leukocytes ; Electrodiagnostic features: Reduction of conduction velocity, conduction 
block or abnormal $\mathrm{F}$ wave in more than one nerve. ; Features casting doubt on the diagnosis: Marked persistent asymmetrical weakness; Persistent bladder or bowel dysfunction. ; Bladder or bowel dysfunction at onset ; Prescence of polymorphonuclear leukocytes in the CSF; Sharp sensory level; Features that rule out the diagnosis: Indication of any metabolic, infections or disease associated with polyneuropathy and Occurrence of a purely sensory symptoms.

\section{Results:}

About sixty children, 32 male and 28 females, age range between $1-\leq 11$ years, half of them are 1 - 5 year of age, (table 1).

Table (1): Age and gender distribution.

\begin{tabular}{|c|c|c|c|c|c|c|}
\hline \multirow{2}{*}{ Age } & \multicolumn{4}{|c|}{ Gender } & \multicolumn{3}{c|}{ Total } \\
\cline { 2 - 7 } & \multicolumn{2}{|c|}{ Male } & \multicolumn{2}{c|}{ Female } & \multicolumn{2}{c|}{} \\
\cline { 2 - 7 } & No. & $\%$ & No. & $\%$ & Total & $\%$ \\
\hline $1-5$ year & 17 & 28.3 & 13 & 12.7 & 30 & 50 \\
\hline $6-10$ & 8 & 13.3 & 6 & 10 & 14 & 23.3 \\
\hline$\leq 11$ & 7 & 11.6 & 9 & 15 & 16 & 26.7 \\
\hline Total & 32 & 53.3 & 28 & 46.7 & 60 & 100 \\
\hline
\end{tabular}

about 27 patients (45\%) had history of antecedent events (table 2). Upper respiratory tract infection (URTI) in (33.3\%), gastroenteritis $(11.7 \%)$ and 6 patients had history of fever, $33(55 \%)$ of patients had no such events (table 2). 53 patients (88\%) had a manifestation of typical GBS, $6(10 \%)$ had Miller Fisher syndrome, 1 (1.6\%) had atypical manifestations (table 2).

Table (2): Antecedent infection of patients with GBS and Clinical manifestations.

Types of previous infection

\begin{tabular}{c}
$\begin{array}{c}\text { Number of } \\
\text { patients }\end{array}$ \\
\hline
\end{tabular}




\begin{tabular}{|l|c|c|}
\hline & (No.) & \\
\hline Upper respiratory tract infection & 14 & 33.3 \\
\hline Gastroenteritis & 7 & 11.7 \\
\hline Fever & 6 & 10 \\
\hline No history of infection & 33 & 55 \\
\hline Total & 60 & 100 \\
\hline Clinical form & & \\
\hline Typical GBS & 53 & 88.3 \\
\hline Miller Fisher & 6 & 10 \\
\hline Atypical & 1 & 1.7 \\
\hline Total & 60 & 100 \\
\hline
\end{tabular}

Cranial nerves involvement was observed in 20 patients (30\%). Motor nerves involvement in 60 (100\%), Sensory manifestation was observed in 10 patients $(16 \%)$ table 3.

Table (3): nerves involvement in 60 patients with GBS and sensory manifestation

\begin{tabular}{|c|c|c|}
\hline Nerves & $\begin{array}{c}\text { Number of } \\
\text { patients }\end{array}$ & $\%$ \\
\hline Cranial & 20 & 30 \\
\hline Sensory & 10 & 16 \\
\hline Motor & 60 & 100 \\
\hline Sensory manifestation & 7 & 11.7 \\
\hline Paresthesia
\end{tabular}




\begin{tabular}{|c|c|c|}
\hline Pain & 12 & 20 \\
\hline No symptoms & 41 & 68.3 \\
\hline Total & 60 & 100 \\
\hline
\end{tabular}

Autonomic nerves involvement was observed in 8 patients (table 4) as $3.3 \%$ (Urine retention; Stool and urine retention and Hypertension), but $86.7 \%$ No involvement (table-4).

Table (4): Autonomic nerves involvement.

\begin{tabular}{|c|c|c|}
\hline Signs and symptoms & $\begin{array}{l}\text { Number of } \\
\text { patients }\end{array}$ & $\%$ \\
\hline Urine retention & 2 & 3.3 \\
\hline Urine inconvenience & 1 & 1.7 \\
\hline Stool and urine retention & 2 & 3.3 \\
\hline Cardiac dysrhythmias & 1 & 1.7 \\
\hline Hypertension & 2 & 3.3 \\
\hline No involvement & 52 & 86.7 \\
\hline Total & 60 & 100 \\
\hline
\end{tabular}

CSF changes as increase protein was observed in (74\%) patients, whilst only $26 \%$ as normal protein (table 5 ).

Table (5): CSF analysis and changes .

\begin{tabular}{|l|c|c|}
\hline CSF examined & NO. & $\%$ \\
\hline High protein & 20 & 74 \\
\hline Normal protein & 7 & 26 \\
\hline Total & 27 & 100 \\
\hline CSF not examined & 33 & 55 \\
\hline
\end{tabular}

Four Patients (6\%) died during acute illness because of respiratory muscles paralysis. 6 patients $(10 \%)$ stayed in hospital for 2 weeks and 20 
patients (33.3\%) between 2 - 4 weeks, 53.3\% patients for 5 - 8 weeks and only 2 patients (3.4\%) more than 8 weeks, (table 6 ).

Table (6): duration of hospitalization and the outcome.

\begin{tabular}{|l|c|c|}
\hline \multicolumn{1}{|c|}{ Time } & NO. & \% \\
\hline $1-2$ weeks & 6 & 10 \\
\hline $2-4$ & 20 & 33.3 \\
\hline $5-8$ & 32 & 53.3 \\
\hline More than 8 weeks & 2 & 3.4 \\
\hline Total & $\mathbf{6 0}$ & $\mathbf{1 0 0}$ \\
\hline Full recovery & 50 & 83.3 \\
\hline Mild weakness & 4 & 6.7 \\
\hline Death & 4 & 6 \\
\hline Total & $\mathbf{6 0}$ & $\mathbf{1 0 0}$ \\
\hline
\end{tabular}

Full recovery occurred in 45 patients (75\%) during 3-month period and 10 patients $(16 \%)$ were discharged with mild weakness after 3 months, 4 patients (6\%) are died (figure 1).

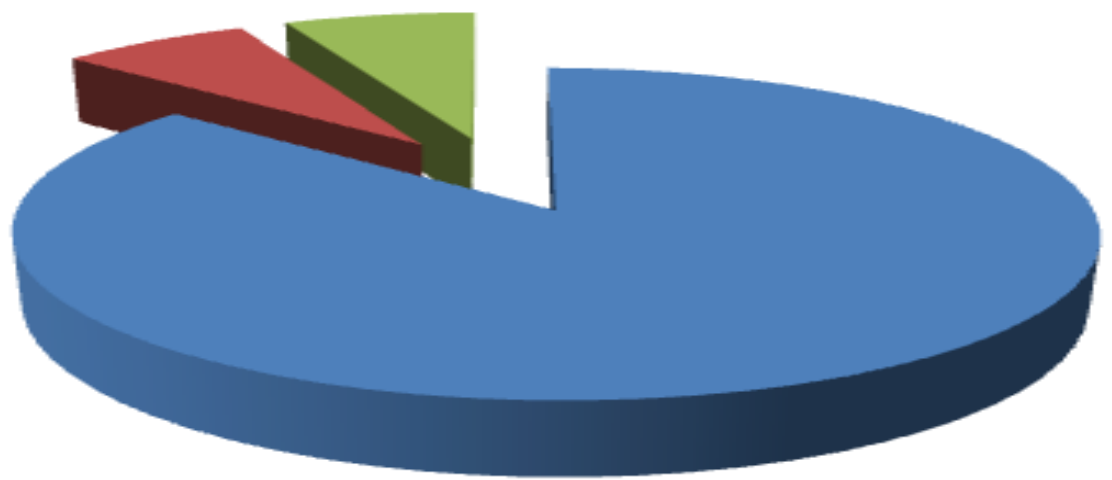

Figure (1): Outcome of patients with GBS (1. full recovery; 2. Mild weakness ;3. Death). 


\section{Discussion:}

The age and sex of the patients were analyzed, it showed that male to female ratio 1-1.1 this is in agreement with beghi etal., which showed male predominance $^{(3) \text {, }}$ so the age distribution in the majority of patients was 1 - 4 years and this in agreement with Hahn ${ }^{(12)}$, Neurological manifestation were preceded by Antecedent events in 27 patients (45\%), of these URTI (32.3\%), gastroenteritis $(11 \%)$, fever in $(10 \%)$ this is in regards to many studies ${ }^{(13,14}$ ,15) ,Ten patients $16 \%$ had sensory symptoms as part of presenting clinical picture of GBS, while Osler ${ }^{(16)}$ minimized the importance of sensory symptoms as part of presenting clinical picture of GBS.

Autonomic nerves involvements were recognized as part of GBS by birchfield ${ }^{(17)}$, in our patients $(15.4 \%)$ had evidence of autonomic dysfunction it was mainly in the form of urine incontinence and retention and cardiac dysrhythmias, however there is no prognostic significance of autonomic dysfunction and unrelated to the degree of paralysis, this is in agreement with $^{(18)}$.

CSF protein was raised in 20 patients $(85.5 \%)$, this is in agreement with rantala etal., ${ }^{(4)}$. Highest value of CSF protein was $(400 \mathrm{mg} / \mathrm{dl})$ and lowest was $(20 \mathrm{mg} / \mathrm{dl})$. Normal CSF protein was found among 7 patients, may be related to the time at which $\mathrm{LP}$ were done, since protein content of CSF raises to its peak between $2^{\text {nd }}-4^{\text {th }}$ week. Normal CSF protein especially early in the illness or finding of normal numerous lymphocytes less than $50 / \mathrm{mm}$ does not exclude diagnosis of GBS. ${ }^{(15)}$

In current study CSF contained up to 35 cell $/ \mathrm{mm}$, majority were lymphocytes, this in agreement with most authors who found that CSF may contain some cells and diagnostic criteria for GBS accepted cell count of less than 50 cell $/ \mathrm{mm}^{(4,14,15)}$ In this study 4 patients died during acute illness giving death rate $(6 \%)$, respiratory failure was found in $25 \%$ and these results are higher than that which was found in a study of Ropper ${ }^{(18)}$.

Recovery over a period of weeks is a Hallmark of GBS and around 50 patients (83.3) have no residual deficit, 4 patients $(6 \%)$ have persistent minor 
problem such as foot drop which does not impair the conduct of everyday Life, this in agreement with Hahn ${ }^{(12)}$. Steroid (methyl prednisolone) was given to 5 Patients, it doesn't affect time of recovery or time of staying in RCU in comparison to those who had not been given and this was in agreement with some studies like that which had been done by Jones ${ }^{(2)}$, so Plasmapheresis was done to only 1 patient with rapidly progressive course with dramatic response and not done to other patients because of unavailability of material and devices which is needed for plasmapheresis of patients' age. This is in agreement with Hahn ${ }^{(12)}$.

\section{References}

1. Robert, P, Cruse, DO . Overview of Guillian Barre syndrome in children , http: up to date . Org. /.15.1_2007.

2. Jones ,HR Jr . Guillian Barre syndrome : perspective with infants and children . Semin pediatric neurology $2000 ; 7: 91$.

3. Beghi, E , Kurland LT , Mulder, DW wiederholt, WC . Guillian Barre syndrome. Clinicoepidemiologic features and effect of influenza vaccine. Arch neurol $1985 ; 42: 1053$.

4. Rantala H, Uhari , M , Niemela , M . Occurrence, clinical manifestations, and prognosis of Guillian Barre syndrome . Arch Dis children 1991; $66: 706$.

5. Olive, JM , Castillo, C, Castro , RG, de Quadros , CA Epidemiologic study of Guillian Barre syndrome in children less than 15 years of age in Latin America. J Infectious dis $1997 ; 175$ suppl $1:$ S160 .

6. Carroll, JE Jedziniak, M, Guggenheim, MA . Guillian Barre syndrome : another cause of the floppy infant . Am J Dis child 1977 ; $131: 699$.

7. Buchwald, B de Baets , M , luijckx , GJ , Toyka , KV . Neonatal Guillian Barre syndrome : blocking antibodies transmitted from mother to child . Neurology $1999 ; 53: 1246$.

8. Griffin, JW , Li , CY, Macko, C, et al. Early nodal changes in the acute motor axonal neuropathy pattern of Guillian Barre Syndrome . J Neurocytology $1996 ; 25: 33$. 
9. Evans , OB , Vedanarayanan , V . Guillian Barre syndrome . Pediatric Rev $1997 ; 18: 10$.

10.Lu , JL , Sheikh, KA, Wu , HS, et al. Physiologic-pathologic correlation in Guillian Barre Syndrome in children . Neurology 2000 ; $54: 33$.

11.Fisher, M . An unusual variant of acute idiopathic polyneuritis (syndrome of opthalmoplegia, ataxia and areflexia) . N Engl J Med $1956 ; 255: 57$.

12.Hahn , AF . The Guillian Barre syndrome . Lancet 1998 ; 352 : 635

13.Patja , A , Paunio , M , Kinnunen , E , et al. Risk of Guillian Barre syndrome after measles-mumps-rubella vaccination . J Pediatric $2001 ; 138: 250$.

14. Steininger, C , popow - Kraupp , T , seiser , A , et al. Presence of cytomegalovirus in cerebrospinal fluid of patients with Guillian Barre syndrome . J Infect disease 2004 :189:984 .

15.Mori , M , Kuwabara , S , Miyake , M , et al. Haemophilus influenzae infection and Guillian Barre syndrome . Brain $2000 ; 123$ (pt 10) :2171.

16. Osler, LD and Heller : GBS N. Engl Med . 1960 , 262 : 964 - 969 .

17.17.Birchfield , RI AND showe . Postural Hypotension in Guillian Barre Syndrome . Arch Neurol . $1964 ; 10$ : 146-157 .

18.Ropper, AH . The Guillian Barre syndrome . N Engl J Med 1992 ; $326: 1130$. 